\title{
PERSPECTIVAS ATUAIS DA GESTÃO LOCAL FACE À EMERGÊNCIA DO EMPREENDEDORISMO URBANO
}

\section{Soliane Bonomo}

Universidade Federal do Espírito Santo

\section{RESUMO}

Este artigo refere-se às possibilidades de adoção de recentes posturas dos governos locais em relação ao desenvolvimento econômico em virtude da ascensão do empreendedorismo urbano. Aborda a transição pela qual esse modelo passou, a valorização da esfera local, bem como o seu discurso focado na fusão entre o interesse público e o interesse privado. Permeiam o trabalho observações acerca das parcerias público-privadas, bem como o potencial e limitações destas enquanto instrumentos de gestão e desenvolvimento urbano. Por fim, enfoca uma discussão inerente às Operações Urbanas Consorciadas, consideradas uma das ferramentas que requerem uma relação mais íntima entre o poder público e a iniciativa privada para serem implementadas.

Palavras-chave: empreendedorismo urbano, parcerias público-privadas, operações urbanas consorciadas.

\section{ABSTRACT}

This paper is about the possibilities of adoption of recent postures of local govermments in relation to economic development due to the rise of urban entrepreneurship. This essay approaches the transaction that this model has, the enhancement of the local sphere as well as the speech focused on merger between public interest and private interest. This work is permeated by observations about public and private partherships besides their potential and limitation while instruments of management and urban development. Finally, itfocus on discussion inherent urban operations Consortion, considered one of the tools that requires one close relation between public power and privite initiative to be implemented. 
KEYWORDS: urban entrepreneurship, public and private partherships, urban operations Consortium.

\section{Considerações iniciais}

Nos últimos anos, as conclusões negativistas sobre a cidade disseminaram-se velozmente. Várias evidências da crise urbana foram alvos desses debates e se manifestam de diversas maneiras, notoriamente sob a forma de violência, pobreza, deficiência de infraestrutura, deterioração ambiental, submoradias, dentre outros.

Paralelamente a esses discursos, propagaram-se debates referentes às transformações no panorama urbano com o florescimento de novos modelos de política urbana baseados na ascensão de um papel dirigente do governo local no fomento do desenvolvimento econômico e no aumento da participação do setor privado na gestão de serviços. Esse novo modelo de gestão, denominado empreendedorismo urbano, tem sua gênese desde meados dos anos 1970, estando diretamente ligado à crise do Estado relacionada com o esgotamento do modelo fordista-keynesiano. A transição desse modelo - administrativo urbano - para o empreendedorismo urbano será apresentada na primeira parte deste artigo, destacando o papel dos governos locais como promotores da adoção de certas práticas político-administrativas inovadoras e apresentando, ao mesmo tempo, a cidade como ator e objeto de uma ação estratégica.

Essa nova postura adotada pelo poder público tem se disseminado rapidamente pelo nosso país e tem como característica principal a formação de parcerias públicoprivadas. Esse assunto será tratado com mais acurácia na segunda parte deste artigo, uma vez que tem figurado no Brasil, principalmente na última década, como uma alternativa para a crise contemporânea e um instrumento de apoio às políticas urbanas locais. Nesse sentido, o assunto das parcerias ganha cada vez mais força na esfera da gestão pública local, porém, envolve certo grau de insegurança em virtude dos riscos de variadas naturezas que as mesmas podem acarretar.

Embora o desejável seja a ausência de riscos, a parte final do texto busca transmitir algumas formas de minimizá-los, apontando alguns instrumentos jurídicos urbanísticos previstos no Estatuto da Cidade. Sem incorrer em aprofundamentos, será dada uma ênfase, dentre esses instrumentos, às Operações Urbanas Consorciadas, 
visto que este é um dos que mais se aproxima da ideia, nos termos da lei, de parceria público-privada. Nessa discussão, serão abordadas algumas opiniões favoráveis ou não à implementação desse instrumento, dando margem à importância de uma reflexão mais aprofundada do mesmo.

\section{Mudança do Administrativo Urbano para o Empreendedorismo Urbano}

Nos dois últimos decênios, é notória a reorientação das posturas das governanças urbanas adotadas nos países capitalistas avançados. A abordagem administrativa, característica dos anos 1960, foi substituída por formas de ação inovadoras e empreendedoras a partir da década de 1970. Segundo Harvey (2005, p.168), há uma concordância geral de que a mudança tem a ver com as dificuldades enfrentadas pelas economias capitalistas a partir da recessão de 1973.

O longo período que antecede a essa recessão compreendido a partir do pós-guerra (1945) foi de grande expansão e se baseou num conjunto de práticas de controle do trabalho, tecnologias, hábitos de consumo e configurações de poder políticoeconômico denominado fordista-keynesiano (HARVEY,1992, p.119).

Esse crescimento da expansão de pós-guerra teve dimensões extraordinárias e esteve subordinado a uma sucessão de compromissos e reposicionamentos por parte dos principais agentes dos processos de desenvolvimento capitalista. De acordo com Harvey:

O Estado teve de assumir novos (keynesianos) papéis e construir novos poderes institucionais; o capital corporativo teve de ajustar as velas em certos aspectos para seguir com mais suavidade a trilha da lucratividade segura; e o trabalho organizado teve de assumir novos papéis e funções relativos ao desempenho nos mercados de trabalho e nos processos de produção. O equilíbrio de poder, tenso, mas mesmo assim firme, que prevalecia entre o trabalho organizado, o grande capital corporativo e a naçãoEstado, e que formou a base de poder da expansão de pósguerra, não foi alcançado por acaso - resultou de anos de luta (HARVEY, 1992,p.125).

Nesse contexto, o Estado se encarregava de diversos compromissos e conforme a produção de massa solicitava condições de procura estáveis para obter lucro, o Estado não poupava esforços para controlar os ciclos econômicos através de políticas fiscais e monetárias no período pós-guerra. Tais políticas eram direcionadas aos setores de investimento público essenciais para o aumento da produção e do consumo de massa que de certa forma possibilitava a garantia de emprego. 
Para Compans (2005, p.47), a intervenção do Estado na regulação da relação salarial era o que permitia prever, compatibilizar e antecipar, sob a forma de salários e benefícios, o aumento geral da produtividade. No entanto, Harvey (1992, p.132) afirma que nem todos eram atingidos pelos benefícios do fordismo, pois a negociação fordista de salários estava confinada a certos setores da economia e a certas naçõesEstado em que o crescimento estável da demanda podia ser acompanhado por investimentos de larga escala na tecnologia de produção em massa.

Em meados dos anos 1960, o fordismo e o keynesianismo apresentavam evidências de não serem capazes de controlar as contradições referentes ao capitalismo. Para Harvey (1992, p.135), essas dificuldades podem ser melhor compreendidas por uma palavra: rigidez.

Segundo Harvey (apud ARANTES;VAINER;MARICATO, 2000, p.129), a marca da rigidez acompanhou o período de acumulação de capital fordista: o grande capital convivia com o grande governo (welfarestate) e com o grande trabalho(gigantescas corporações sindicais). A esse respeito, Harvey ainda comenta:

Havia problemas com a rigidez dos investimentos de capital fixo de larga escala e de longo prazo em sistemas de produção em massa que impediam muita flexibilidade de planejamento e presumiam crescimento estável em mercados de consumo invariantes. Havia problemas de rigidez nos mercados, na alocação e nos contratos de trabalho(...) A rigidez dos compromissos do Estado foi se intensificando à medida que programas de assistência (seguridade social, direitos de pensão etc.) aumentavam sob pressão para manter a legitimidade num momento em que a rigidez na produção restringia expansões de base fiscal para gastos públicos. O único instrumento de resposta flexível estava na política monetária, na capacidade de imprimir moeda em qualquer montante que parecesse necessário para manter a economia estável (HARVEY, apud ARANTES; VAINER; MARICATO, 2000, p.129).

Qualquer tentativa para a superação desses problemas de rigidez encontrava a resistência da classe trabalhadora, que conforme Compans (2005, p.48) pressionava através das ondas de greves a ampliação dos benefícios do Estado do Bem-Estar Social aos desempregados e imigrantes que haviam sido mantidos "fora" do pacto fordista.

De acordo com Arantes; Vainer; Maricato (2000, p.22), nos anos 1960, a cena das cidades americanas fora invadida por manifestações pelos direitos civis, demonstrações contra a guerra no Sudeste Asiático e motins de toda espécie, URBANA, V.4, no5, dez.2012 - Dossiê: Cidades e Sociabilidades - CIEC/UNICAMP 
sobretudo nos bairros negros, sendo que boa parte do descontentamento urbano girava em torno dos projetos "modernos" de habitação e renovação dos equipamentos funcionais típicos, ameaçados no momento por distúrbios que estavam se tornando endêmicos.

Portanto, a crise de 1973-1975 derivou em parte de um confronto com a rigidez acumulada de práticas e políticas de governo implantadas no período fordistakeynesiano. As políticas keynesianas tinham se mostrado inflacionárias à medida que as despesas públicas cresciam e a capacidade fiscal estagnava (HARVEY, 1992, p.157).

Esse autor ainda assegura que essa crise, exacerbada pelo choque do petróleo, evidentemente retirou o mundo capitalista do sufocante torpor da "estagflação" (estagnação da produção de bens e alta inflação de preços) e pôs em movimento um conjunto de processos que solaparam o compromisso fordista.

Características marcantes do "esquema tradicional", segundo Compans (2005, p.50), seriam então abandonadas em todo o mundo e em especial uma delas seria substituída por uma política diametralmente inversa: a da busca da atração das empresas estrangeiras. Dessa forma, Harvey (1992, p.158) salienta que o aumento da competição internacional em condições de crescimento lento forçou todos os estados a se tornarem mais "empreendedores' e preocupados em manter um clima favorável aos negócios. E afirma ainda: o empreendimentismo inovador e "esperto" foi bastante valorizado, ajudado e estimulado pelos atavios da tomadas de decisões rápida, eficiente e bem fundamentada.

Nesse contexto, o empreendedorismo urbano toma sobre si a direção na formulação da política urbana e nas estratégias de desenvolvimento urbano e a emergência do mesmo pode ter desempenhado um papel fundamental na passagem da dinâmica do capitalismo de um sistema fordista-keynesiano de acumulação capitalista para um sistema de "acumulação flexível". Assim, pode-se afirmar que:

As mudanças na política urbana e o movimento rumo ao empreendedorismo têm desempenhado um importante papel facilitador na transição dos sistemas de produção fordistas localizacionalmente rígidos, suportados pela doutrina do bem-estar estatal keynesiano, para formas de acumulação flexível muito mais abertas em termos geográficos e com base no mercado. Além disso, pode-se afirmar que a transição do modernismo de base urbana para o pós-modernismo, com relação ao design, às URBANA, V.4, no5, dez.2012 - Dossiê: Cidades e Sociabilidades - CIEC/UNICAMP 
formas culturais e ao estilo de vida, também está conectada à ascensão do empreendedorismo urbano (HARVEY, 2005, p.181).

Para Compans (2005, p.139), à medida que os Estados estariam se tornando cada vez mais meros mecanismos burocráticos, desvitalizados de sua anterior representatividade política e do poder regulatório que os permitia planejar e estimular a economia, os governos locais despontariam como agentes potencialmente articuladores de redes sociais cooperativas e mobilizadores de recursos internos e externos

O empreendedorismo urbano abrange determinado nível de concorrência interurbana que conduz à reificação da cidade como empresa e ao mesmo tempo como mercadoria. Dessa forma, Arantes; Vainer;Maricato (2000, p.87) comentam que a cidade que saiu da forma passiva de objeto e assumiu a forma ativa de sujeito ganha uma nova identidade: é uma empresa. Esclarecem ainda que a cidade é uma mercadoria a ser vendida, num mercado extremamente competitivo, em que outras cidades também estão à venda.

Nesse sentido, Borja e Forn (apud COMPANS, 2005, p.27) afirmam que a mercadotecnia da cidade, vender a cidade, converteu-se [...] em uma das funções básicas dos governos locais e um dos principais campos de negociação públicoprivada.

O discurso do empreendedorismo utiliza-se, portanto, dessa linguagem figurada, metafórica - na qual a cidade torna-se "empresa", equipamentos, serviços e trabalhadores tornam-se "mercadorias", e a competitividade das empresas torna-se "competitividade da cidade" - como um recurso discursivo pelo qual se atribuem novos papéis e objetivos à administração urbana (COMPANS, 2005, p.27). Desse modo, vender a imagem das cidades, suas peculiaridades e suas qualidades como atrativos locacionais compõe uma das bases da atuação empreendedorista dos governos locais.

\section{Efeito da emergência do empreendedorismo urbano: a formação de parcerias público-privadas}

A característica central do empreendedorismo urbano consiste na formação de parcerias público-privadas - PPPs -, em que a iniciativa tradicional local se completa com a utilização dos poderes governamentais locais, procurando e persuadindo fontes 
externas de financiamento, e novos investimentos diretos ou novas fontes de emprego. Para Arantes;Vainer;Maricato (2000, p.87), a parceria público-privada assegurará que os sinais e interesses do mercado estarão adequadamente presentes, representados, no processo de planejamento e decisão.

A instituição das parcerias entre os setores público e privado não é propriamente inovadora. Segundo Brito (2005?, p.7), essa ideia surgiu na Europa, mais especificamente na Inglaterra, durante o governo de Margareth Thatcher, num contexto de escassez de recursos públicos e necessidade de investimentos em projetos de grande escala.

Sob o enfoque econômico, as parcerias público-privadas representam uma ideia bastante antiga. No Brasil e em outros países, antes mesmo da formação dos Estados nacionais, já se observava a prática de acordos entre o setor público e a iniciativa privada. Como exemplos embrionários citam-se:

As expedições exploratórias de navegação e o próprio sistema de capitanias hereditárias, por exemplo, podem ser entendidos como exemplos embrionários de PPPs, feitas entre a coroa portuguesa e os capitalistas europeus. É fato também que durante o Império (1822 a 1889), parte significativa da infra-estrutura ferroviária, de telecomunicações e iluminação pública implantada no país foi viabilizada por meio de parcerias entre os dois setores, com forte presença inglesa do lado privado (BRITO, 2005?, p.07).

Portanto, a realização de parcerias entre o público e o privado remontam ao período imperial brasileiro e, no sentido mais amplo, ao próprio aparecimento do capitalismo. Dessa forma, nas palavras de Di Pietro (apud BRITO, 2005?, p.01), esse parece ser um dos casos de "institutos velhos que renascem com nova força e sob novo impulso" ou que aparecem com "nova roupagem".

Porém, na última década, renasce com nova força e sob novo impulso discursos fundamentados na criação de parcerias público-privadas como uma espécie de solução para a crise contemporânea brasileira. Essa questão tem estado presente em muitos debates, que para Brito (2005?, p.08) esta tem sido a melhor (para alguns, a única) alternativa viável para tentar minimizar, no curto e no médio prazo, a falência do Estado brasileiro na provisão de bens e serviços públicos de qualidade.

A gravidade da crise fiscal brasileira nem precisa ser colocada em discussão, uma vez que grande parte das cidades de nosso país está estacionada financeiramente. Fazendo um paralelo entre essa problemática e a falência do modelo de planejamento 
modernista/funcionalista e a força ideológica dos argumentos neoliberais, Maricato (2002, p.04) comenta porque a efetivação de parcerias com a iniciativa privada passa a ser vista como uma tábua de salvação para muitas prefeituras, sejam elas conservadoras ou progressistas. Nesse sentido, essa tem sido a iniciativa mais oportuna no contexto atual para equacionar a crise financeira e infraestrutural das cidades.

Atualmente, o Brasil e a sociedade civil contam com um marco legal claro e definido para a implementação de parcerias público-privadas (PPPs), a Lei no 11.079, de 30 de dezembro de 2004, que "institui normas gerais para licitação e contratação de parceria público-privada no âmbito da administração pública". Segundo essa lei, a parceria público-privada é:

"contrato administrativo de concessão, na modalidade patrocinada ou administrativa" (Art. $2^{\circ}$ ), sendo a primeira a concessão de serviços públicos ou obras públicas que envolvem, "adicionalmente à tarifa cobrada dos usuários, uma contraprestação pecuniária do parceiro público ao parceiro privado" ( $\left(1^{\circ}\right)$; e a segunda, "o contrato de prestação de serviços de que a Administração Pública seja a usuária direta ou indireta, ainda que envolva execução de obra ou fornecimento e instalação de bens" ( $§ 2^{\circ}$ ).

Do ponto de vista legal, o texto de lei aprovado define claramente as PPPs como uma modalidade de contrato de concessão, seja a patrocinada, seja a administrativa. No entanto, Pinto (2005, p.02) adverte que o desafio que agora se impõe é passar do texto legal para a realidade da implementação dos projetos concebidos.

O ponto mais polêmico das discussões inerentes à ascensão das PPPs é ter conhecimento do quanto esse acordo poderá ser realmente favorável ao interesse público. Para Brito (2005?, p.08), o cerne da questão é compreender em que medida esse processo de interação reflete um avanço na forma de gestão pública ou um retrocesso no sentido do patrimonialismo, da promiscuidade entre o público e o privado ou de um retorno ao liberalismo.

O sucesso das PPPs depende do interesse que elas possam gerar no investidor privado. Para Pinto (2005, p.03), esse interesse será maior ou menor em função do resultado da equação remuneração versus risco. Harvey (2005, p.173) complementa que a atividade da parceria público-privada é empreendedora, pois, na execução e no projeto, é especulativa, e, portanto, sujeita a todos os obstáculos e riscos associados 
ao desenvolvimento especulativo, ao contrário do desenvolvimento racionalmente planejado e coordenado.

Os riscos num projeto PPPs são de várias naturezas: políticos, ambientais, contratuais, etc. Porém, não se percebe muitas evidências dos impactos negativos que tais parcerias podem acarretar, uma vez que os aspectos positivos e de sucesso das mesmas costumam ter um maior destaque pela mídia e pelo discurso oficial do governo.

De acordo com Santana e Júnior (2006, p.35), a grande justificativa de quem defende as PPPs é, invariavelmente, o seu tom otimista e de fé no grande investidor, especialmente o investidor internacional. No entanto, esse positivismo e confiança provocam incertezas ao darmos conta de que os setores almejados pelo governo para receberem investimentos do capital privado não costumam ser de interesse desse mesmo capital.

Para que o capital privado se interesse por tais empreendimentos, é necessário que o Estado os torne bastante lucrativos e nesse sentido, a aplicação da Lei de PPPs poderá converter determinados serviços públicos em mercadoria atraente e bastante vantajosa em termos de mercado. Mediante essa crítica, Santana e Júnior (2006, p.01) enfatizam alguns dos males de que padecem as PPPs: a ideia de PPP cria demasiadas facilidades para o capital privado; compromete a própria essência daquilo que se chama de serviço público; favorece um tipo de política pública que já não será mais universal e sim focal; e, finalmente, representa a mercantilização dos serviços públicos típicos ou promovidos exclusivamente pelo Estado e viabilizam o interesse do capital financeiro internacional.

Nessa perspectiva, deve-se reconhecer que, sob a camuflagem de muitos projetos de sucesso, existem alguns problemas sociais e econômicos muito sérios, e que isso, em muitas cidades, está assumindo um caráter geográfico, na forma de uma cidade dupla, com a regeneração de um centro de cidade decadente e um mar circundante de pobreza crescente. (HARVEY, 2005, p.188).

Nesse contexto, não há operação sem riscos e um caminho para alcançar a eliminação ou a ausência dos mesmos é procurar minimizá-los. Para dar suporte às parcerias, os governos locais podem utilizar alguns instrumentos de cooperação público-privada previstos no Estatuto da Cidade. É o que abordaremos a seguir. 


\section{Instrumentos Jurídicos Urbanísticos: Uma reflexão sobre a Operação Urbana}

\section{Consorciada}

Em vigor desde 10 de outubro de 2001, a lei $\mathrm{n}^{\circ} 10.257$, mais conhecida como Estatuto da Cidade, estabelece as diretrizes gerais da política urbana visando principalmente o amplo desenvolvimento das funções da cidade e a garantia ao direito a cidades sustentáveis. Essa tarefa é atribuída aos governos locais, oferecendo às cidades um conjunto inovador de ferramentas de intervenção e ordenamento de seus territórios, além de uma nova visão acerca de planejamento e gestão urbana e territorial.

Essas inovações correspondem a três campos: a) um conjunto de instrumentos de natureza urbanística direcionados a induzir as formas de uso e ocupação do solo; b) uma concepção de gestão democrática que incorpora a ideia de participação direta do cidadão nos processos decisórios; c) e o aumento das chances de regularização das posses urbanas.

Para dar suporte às formas de parceria público-privada na esfera local, os municípios, por meio de seus Planos Diretores, podem utilizar alguns instrumentos previstos no Estatuto da Cidade que estabelece as diretrizes gerais da política urbana. Dentre os instrumentos que requerem uma articulação mais estreita entre o poder público e a iniciativa privada para serem implementados, destacam-se a outorga onerosa do direito de construir e de alteração de uso, o consórcio imobiliário e as operações urbanas consorciadas.

Segundo Brito (2005?, p.37), a operação urbana consorciada é o instrumento mais explicitamente caracterizável, nos termos da lei, como parceria público-privada. Isto porque a escala dos empreendimentos e o grau de comprometimento do capital privado são condições inerentes para a realização de uma Operação Urbana Consorciada (OUC). Conforme o artigo 32, parágrafo $1^{0}$ do Estatuto da Cidade, são consideradas operações urbanas consorciadas:

(...) o conjunto de intervenções e medidas coordenadas pelo Poder Público Municipal, com a participação dos proprietários, moradores, usuários permanentes e investidores privados, com o objetivo de alcançar em uma área transformações urbanísticas estruturais, melhorias sociais e a valorização ambiental.

No entanto, a Operação Urbana Consorciada não é um instrumento inovador e já apareceu, sob configurações e nomenclaturas variadas, em planos diretores de 
diversas cidades brasileiras. Em São Paulo, esse instrumento foi precedido do mecanismo Operação Interligada, criado pela Lei Municipal 10 209/86 e alterado pela Lei 11 773/95, pelo qual a iniciativa privada doava à prefeitura um determinado número de habitações de interesse social em troca de modificações dos índices urbanísticos e categorias de uso nos terrenos de sua propriedade. No entanto, por iniciativa do Ministério Público, foi suspensa, desde 1998, por inconstitucionalidade e está de volta no texto do Estatuto da Cidade, mas atrelada ao Plano Diretor.

As Operações Urbanas Consorciadas foram introduzidas em um contexto de empreendedorismo, no qual o poder público local busca uma alternativa para a concretização das metas e diretrizes estabelecidas no Plano Diretor (MACEDO, 2007, p.50). Assim, a execução de operações urbanas é de competência municipal, uma vez que este é o ente federativo que dá impulso à política urbana. Portanto, trata-se de uma função pública não passível de ser delegada para o setor privado. Cabe ao município escolher a área para efetivar uma operação urbana. Contudo, para que a parceria seja possível, é preciso que o município tenha certeza de que a área selecionada vai interessar o capital imobiliário.

Como outros instrumentos propostos no Estatuto da Cidade, as operações urbanas consorciadas podem ser positivas ou negativas, dependendo da forma como foram incluídas e detalhadas nos planos diretores. Nesse aspecto, intensificam-se as opiniões inerentes à eficácia ou não da possibilidade do cumprimento da função social da propriedade por meio das operações urbanas consorciadas.

Alguns urbanistas, como Mendonça (apud MOREIRA e ARAÚJO, 2007, p.09) defendem as operações urbanas consorciadas por acreditar que essas seriam mecanismos de coibição de processos especulativos do solo urbano, de resgate para os cofres públicos da valorização imobiliária decorrente de obras públicas, enfim, mecanismos de cumprimento da função social da propriedade urbana.

O consenso em volta das operações urbanas se deve à aceitação que vem ganhando a ideia de se efetivar parcerias entre o poder público e os variados atores sociais na gestão da cidade, como meio de vencer os obstáculos enfrentados pelo Estado. Nesse sentido, Maricato (2002, p.04) enfatiza que as operações urbanas são justificadas por uma maioria como um instrumento importante para uma nova e moderna forma de gestão concertada, adaptada às contingências da nova economia. 
Guimarães (2004, p.239) afirma que o objeto da operação urbana consorciada é a transformação urbanística estrutural, a melhoria social e a valorização ambiental. Contudo, Maricato $(2002$, p.01) questiona: as operações urbanas poderão ser utilizadas de fato para engendrar "melhorias sociais" e "valorização ambiental" como reza o Estatuto da Cidade? Para essa autora, muito da polêmica que gira em torno da modalidade anterior às operações urbanas, ou seja, as operações interligadas, se deve à maneira como elas foram efetivadas em São Paulo, município que levou essa experiência mais longe, alimentando lucros do capital imobiliário de ponta e ignorando, ou melhor, reproduzindo e agravando problemas sociais.

Nesse sentido, a Operação Urbana Consorciada tende a obter mais êxito na área em que existe maior pressão do mercado imobiliário, levando a concentração dos investimentos para as regiões aonde eles já estão concentrados, aumentando, dessa forma, as desigualdades intraurbanas.

Nessa perspectiva, o elemento que incentiva as operações urbanas não é um projeto urbanístico preparado pelo poder público e sim, uma resposta às demandas do setor imobiliário. Para Maricato (2002, p.10), esse instrumento perde o caráter urbanísticosocial, uma vez que o mesmo torna-se um fim em si, apenas como elemento de alavancagem de uma mega-operação imobiliária. Cardoso (apud SOUZA, 2006, p.276) também chama atenção a essa questão, quando afirma que experiências entre o público e o privado realizadas anteriormente, como as operações "Faria Lima", "Anhangabaú" e "Córrego Águas Espraiadas", mostraram o quanto esse instrumento pode ser útil ao capital imobiliário, ao mesmo tempo que presta tão poucos serviços à população de baixa renda. Esse autor ressalta que no caso do Córrego Águas Espraiadas, operação proposta ainda na gestão Erundina, mas realizada e modificada na gestão Maluf, os efeitos foram extremamente perversos:

Como existia uma área de ocupação de baixa renda, com extremo potencial de valorização, e como não foram desenvolvidas políticas específicas para manter os ocupantes no local, ela foi "liberada" através da ação dos empresários. A população que ali residia foi, em grande parte, engrossar o processo de ocupação das áreas de mananciais (CARDOSO, apud SOUZA, 2006, p.276).

Para Souza (2006, p.277), os resultados poderiam ter sido diferentes se o instrumento utilizado na época tivesse sido modelado com a intenção de servir ao propósito de que a Prefeitura assumisse a coordenação técnica da implantação de 
infraestrutura e da ocupação de uma dada área, enquanto o setor privado forneceria os recursos necessários para a obra.

Assim, ao poupar uma grande parcela de seus reduzidos recursos e direcioná-los na realização de melhoramentos em espaços segregados e escassos de infraestrutura, o Estado estaria invertendo as prioridades e contribuindo para uma redistribuição de riqueza socialmente produzida. De acordo com Di Giuseppe (2001, p.379), esse mecanismo de reversão dos recursos à municipalidade confere às Operações Urbanas um caráter redistributivo, na medida em que ingressos oriundos do setor privado venham a ser aplicados em obras, melhorias, equipamentos ou programas de interesse da coletividade. Encaradas dessa forma, as operações urbanas possuem um potencial de contribuição muito grande para o desenvolvimento urbano, e, diferentemente do que sugere Cardoso (apud SOUZA, 2006, p.278), esses instrumentos não precisam ser vistos, necessariamente, como um "equívoco" da agenda da reforma urbana.

Nesse aspecto, Souza (2006, p.280) salienta que as operações urbanas consorciadas não precisam ser demonizadas, mas tampouco devem ser reverenciadas como incorruptíveis: podem ser entendidas como potencialmente benéficas, contanto que a sua regulamentação afaste o perigo de utilizações que sirvam tão somente aos interesses empresariais.

\section{Considerações finais}

As reflexões acerca do exposto não se esgotam neste trabalho, pelo contrário, este estudo dá margem a novos debates que se justificam pelas constantes e intensas polêmicas que giram em torno da implementação das Operações Urbanas Consorciadas.

As Operações Urbanas Consorciadas são consideradas por muitos como um importante instrumento para uma nova e moderna forma de gestão. Porém, se multiplicam as perspectivas pessimistas em relação à implementação das mesmas e, por isso, é imprescindível gerar mais discussões sobre a forma como esse instrumento será efetivado, pois sua regulamentação inadequada pode trazer - ou continuar trazendo - resultados meramente imobiliários, sem mostrar indícios de melhoria do espaço urbano. 
Em virtude das eventuais expulsões da população residente na área de intervenção, as Operações Urbanas acabam funcionando como um instrumento que aumenta a exclusão social e um dos caminhos alternativos para minimizar tal impacto consistiria na gestão compartilhada da operação, com representatividade da sociedade civil, dando oportunidade, assim, ao seu caráter democrático.

Portanto, o cerne da discussão não é definir se as Operações Urbanas Consorciadas devem ou não existir em nosso país. O que está em questão são os cuidados que se deve tomar no momento da formulação desse instrumento, para que ele desempenhe um papel gerador de alguma democratização do espaço urbano.

\section{Referências bibliográficas}

ARANTES, Otília Beatriz Arantes, MARICATO, Ermínia; VAINER, Carlos (2002). A cidade do pensamento único: desmanchando consensos. Petrópolis: Editora Vozes. BRITO,Manuelita Falcão (2005). A cantiga das parcerias público-privadas na gestão urbana local. Disponível em: <http://www.fundaj.gov.br/notitia>. Acesso em 10 jun. 2008.

COMPANS, Rose (2005). Empreendedorismo urbano: entre o discurso e a prática. São Paulo: Editora Unesp.

DI GIUSEPPE, Diana (2001). Operações Urbanas Consorciadas. In: Fundação Prefeito Faria Lima - CEPAM. Estatuto da Cidade. São Paulo.

ESTATUTO DA CIDADE: Guia para implementação pelos municípios e cidadãos (2005). $4^{a}$ ed. Brasília.

GUIMARÃES, Nathália Arruda (2004). Os municípios e o Estatuto da Cidade. Rio de Janeiro: Temas \&Idéias Editora Ltda.

HARVEY, David (2005). A produção capitalista do espaço. São Paulo: Editora Annablume.

(2007). Condição pós-moderna: uma pesquisa sobre as origens da mudança cultural. São Paulo: Edições Loyola.

MACEDO, Mariana Michel de (2007). Operação Urbana Consorciada: uma alternativa para a urbanificação das cidades. Dissertação (Mestrado em Direito do Estado). Programa de Pós-Graduação da Faculdade de Direito, Universidade Federal do Paraná. 
MARICATO, Ermínia; FERREIRA, João Sette Whitaker (2002). Operação Urbana Consorciada: diversificação urbanística participativa ou aprofundamento da desigualdade? In: OSORIO, L.M. (Org.). Estatuto da Cidade e Reforma Urbana: novas perspectivas para as cidades brasileiras. Porto Alegre/São Paulo, Sérgio Antônio Fabris Editor.

MOREIRA, Ana Luísa Nogueira; ARAúJO, Marinella Machado (2007). Operações Urbanas Consorciadas no Estatuto da Cidade. Disponível em: < http://www.conpedi.org.br/manaus/anais_campos.htm> Acesso em: 10 jun. 2008. PINTO, José Emilio Nunes (2005). A percepção de risco nas parceiras público-privadas e a Lei no 11 079/2004 e seus mitigantes. Informativo Jurídico Consulex, Brasília, v. 19, n. 4, p. 3-7, 31 jan 2005.

SANTANA, Gilson Dantas; JúNIOR, Hélio de Souza Rodrigues (2006). As parcerias público-privadas: solução ou problema? Prismas: Dir., Pol. Pub. e Mundial. Brasília, v. 3, n. 1, p. 148-181, jan./jun.

SOUZA, Marcelo Lopes (2006). Mudar a cidade: uma introdução crítica ao planejamento e à gestão urbanos. Rio de Janeiro: Bertrand Brasil. 